\title{
Photoluminescence and Raman spectroscopies as an optical approach of stress determining in MOVPE grown quantum cascade laser structures
}

\author{
Adriana ŁOZIŃSKA ${ }^{1}$, MiKOŁaJ BADURA ${ }^{1}$, JoANNA JADCZAK ${ }^{2}$, \\ KATARZYNA BIELAK ${ }^{1}$, BEATA ŚCIANA ${ }^{1}$ \\ ${ }^{1}$ Faculty of Microsystem Electronics and Photonics, Wrocław University of Science and Technology, \\ Janiszewskiego 11/17, 50-372 Wrocław, Poland \\ ${ }^{2}$ Faculty of Fundamental Problems of Technology, Wrocław University of Science and Technology, \\ Wybrzeże Wyspiańskiego 27, 50-370 Wrocław, Poland
}

${ }^{*}$ Corresponding author: adriana.lozinska@pwr.wroc.pl

In the presented work, an optical approach of stress determining in metalorganic vapor phase epitaxy (MOVPE) grown quantum cascade laser (QCL) structures was reported. In the case of such sophisticated structures containing hundreds of thin layers, it is important to minimize the stress generated in the QCL core. Techniques enabling determination of stress in such thin layers as those described in the article are photoluminescence and Raman spectroscopies. Based on Raman shift or changes in photoluminescence signal, it is possible to analyze stress occurring in the structure.

Keywords: QCL core, photoluminescence, Raman spectroscopy.

\section{Introduction}

Quantum cascade laser (QCL) is a unipolar device based on intersubband transitions [1]]. Due to the possibility of emitting wavelengths in the $\mathrm{THz}$ range, InGaAs/AlInAs heterostructures lattice-matched to InP substrate are most commonly used [2] . Core of QCL contains hundreds or even thousands repetitions of quantum wells and barriers with a thickness on the order of half to ten nanometers [3] . Such a sophisticated structure requires technology with a resolution of the nanometers or even few angstroms order. One of the epitaxial growth methods that provide such resolution is metalorganic vapor phase epitaxy (MOVPE) [4]. This is a chemical epitaxial technique, which means that it is very challenging to control all chemical reactions occurring during the growth process [ $\underline{5}$ ]. One of the critical technological parameters is temperature, which affects the kinetics of growth. Generally in MOVPE technology, the growth temperature is in 
the range of $650-680^{\circ} \mathrm{C}[\underline{2}, \underline{6}]$. It is important to determine the influence of growth temperature on the quality of QCL structures. Photoluminescence (PL) and Raman spectroscopies allow to analyse the interfaces quality and occurring stress in QCL core in a non-destructive and quick way. Raman shift or changes in a photoluminescence signal testify of the character of the structure deviating from the project assumptions.

The paper presents the possibility of using PL and Raman spectroscopies to analyze interfaces and stress in such sophisticated structures as QCL core based on $\operatorname{In}_{0.53} \mathrm{Ga}_{0.47} \mathrm{As}$ / $\mathrm{Al}_{0.48} \mathrm{In}_{0.52}$ As superlattices.

\section{Experiment details}

Epitaxial growth was realised using LP-MOVPE AIXTRON $3 \times 2$ " FT system at pressure lowered to 100 mbar. As sources of group-V elements were used the $100 \%$ concentrated $\mathrm{AsH}_{3}$ and $\mathrm{PH}_{3}$, while TMGa, TMAl and TMIn were group-III precursors. Pure hydrogen was used as a carrier gas. First step was to grow at $645^{\circ} \mathrm{C}$ of four structures contained in the core of the quantum cascade laser capped by $100 \mathrm{~nm} \mathrm{InP.} \mathrm{One}$ of them was left as a reference (P199), then other samples were reloaded and $1.5 \mu \mathrm{m}$ InP top claddings were deposited on each of them at different temperatures 600,645 and $680^{\circ} \mathrm{C}$ (samples P202, P201 and P203, respectively). Scheme of the deposited samples is presented in Fig. 1.

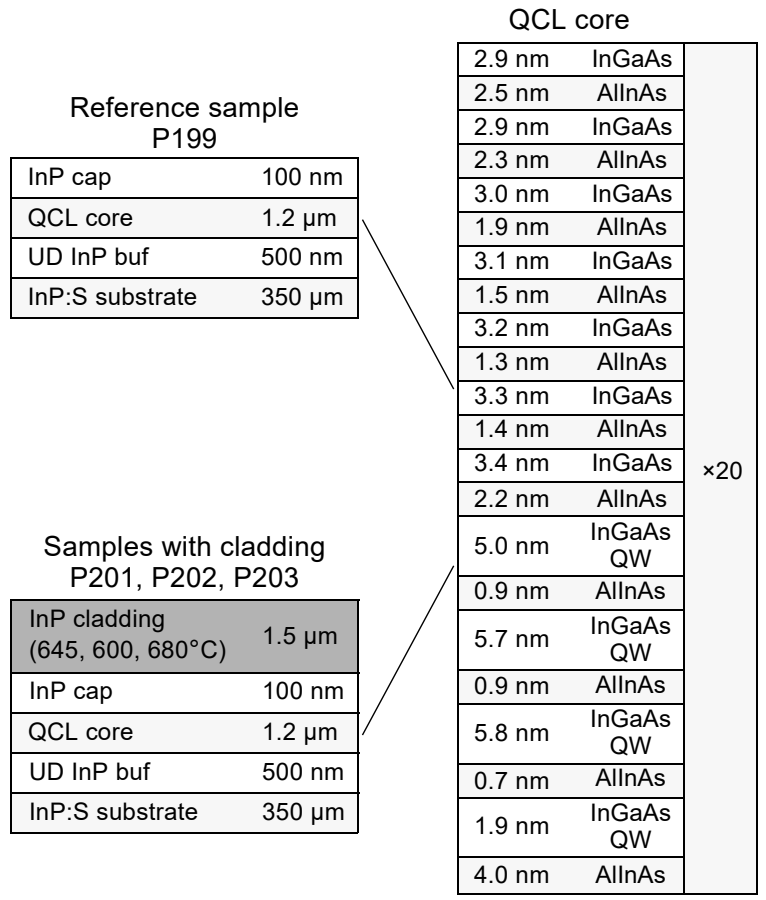

Fig. 1. A sectional view of the investigated QCL structures. 
Raman spectra were measured at room temperature under ambient conditions by a micro-Raman spectrometer (Renishaw inVia Raman Microscope) in a backscattering configuration with excitation provided by $532 \mathrm{~nm}$ line of a diode-pumped solid state laser. The diameter of an excitation spot was equal to $1.5 \mu \mathrm{m}$. The system was equipped with a single-pass spectrometer with a grating of 1800 grooves $/ \mathrm{mm}$ and a Peltier-cooled $\mathrm{CCD}$ array. The optical power was kept on the level of $25 \mathrm{~mW}$. Raman maps were measured by the cross-section with the lateral spatial resolution of $(0.5 \pm 0.1) \mu \mathrm{m}$.

PL spectra were measured at low temperature $(90 \mathrm{~K})$ using AlGaAs/GaAs laser excitation of $641 \mathrm{~nm}$ (continuous wave $\mathrm{CW}$, optical power 1-5 mW). As a detector, the StellarNet DW ARF-STAR NIR-100 spectrometer was employed (InGaAs photodiode, $600 \mathrm{~g} / \mathrm{mm}$, integration time $100 \mathrm{~ms}, 0.5 \mathrm{~nm}$ resolution).

\section{Results and discussion}

Characteristic phonon lines of semiconductor crystals, related to optical longitudinal (LO) and transverse (TO) phonons are observed in the Raman spectrum. Signals in the Raman spectra coming from the compounds discussed in the article should be observed in the
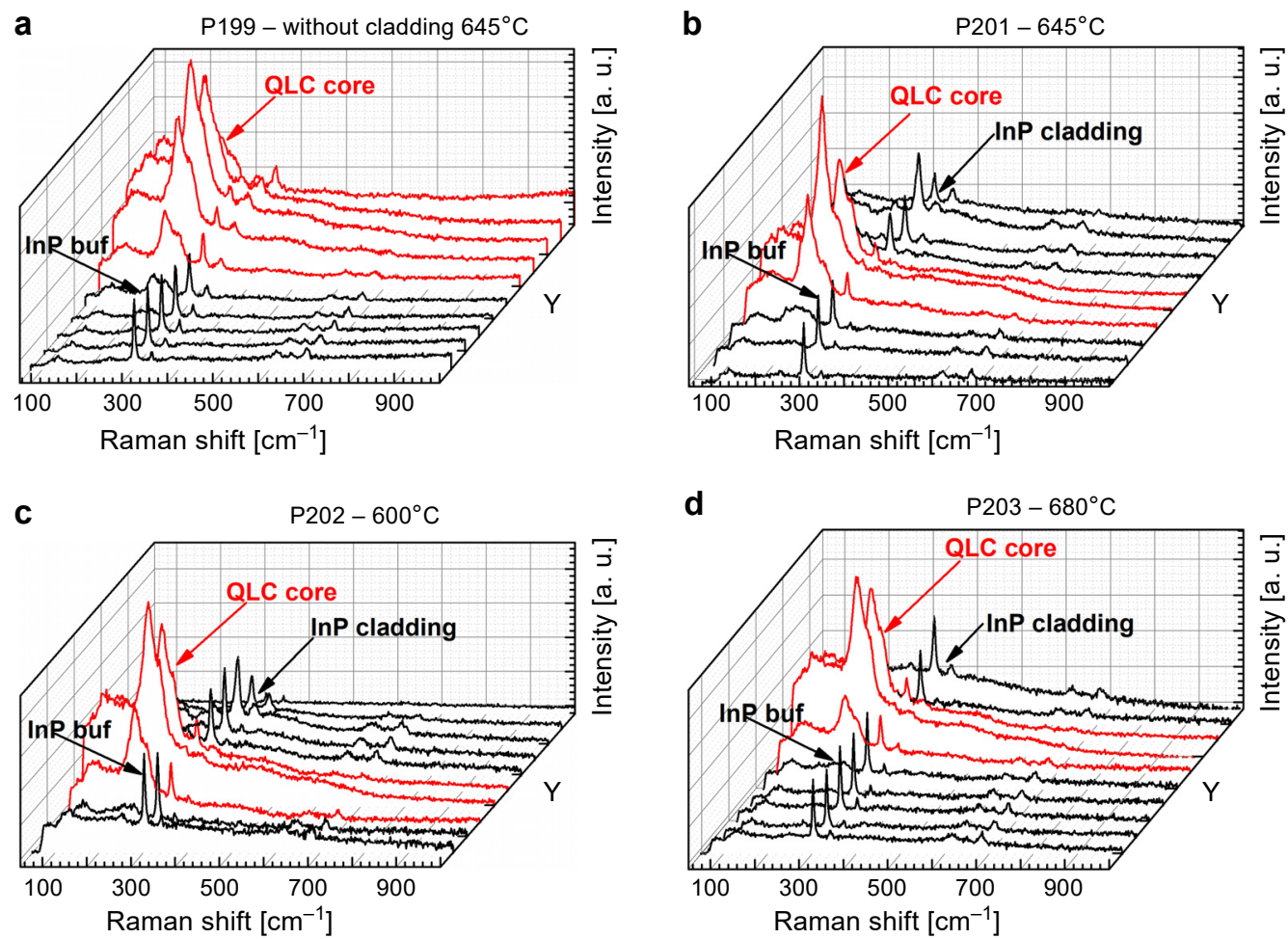

Fig. 2. Raman spectra of sample $\mathrm{P} 199$ - without cladding grown at $645^{\circ} \mathrm{C}$ (a) and three with cladding grown at $645^{\circ} \mathrm{C}-\mathrm{P} 201$ (b), $600^{\circ} \mathrm{C}-\mathrm{P} 202$ (c), $680^{\circ} \mathrm{C}-\mathrm{P} 203$ (d), measured by the cross-section with a $0.5 \mu \mathrm{m}$ step. 
range of $200-300 \mathrm{~cm}^{-1}$ for $\operatorname{In}_{0.53} \mathrm{Ga}_{0.47} \mathrm{As}, 200-370 \mathrm{~cm}^{-1}$ for $\mathrm{Al}_{0.48} \mathrm{In}_{0.52} \mathrm{As}$ [ $\left.\underline{7}\right]$ and $300-350 \mathrm{~cm}^{-1}$ for InP [] . Raman spectra of four samples measured by the cross-section are shown in Fig. 2.

Based on measured Raman spectra, signals from individual layers, i.e. cladding InP and QCL core were derived. In the case of the P199 sample, a slight input of the signal from InP in the QCL core range is observed, due to the fact that this sample did not have 1.5 cladding, but only a $100 \mathrm{~nm}$ cap (Fig. 2a). In the Raman spectra of the other samples (P201-P203), characteristic signals from the InP cladding and QCL core layers are observed. The position of phonon lines in the samples in relation to the reference sample (P199) was changed, which may indicate the occurrence of stress in the structure.

The Raman shift may be due to a crystal symmetry disorder, which can be associated with defects or changes in the composition of the layer. Based on Raman shift values of the phonon lines $\Delta \omega_{\mathrm{LO}}$ and $\Delta \omega_{\mathrm{TO}}$ in relation to the frequency $\omega_{0}$ corresponding to LO and TO phonon lines of the reference sample P199, the value of the stress $\sigma$ in the structure can be determined. Raman shift values $\Delta \omega_{\mathrm{LO}}$ and $\Delta \omega_{\mathrm{TO}}$ are described by the formulas $[\underline{9}, \underline{10}]$ :

$$
\begin{aligned}
& \Delta \omega_{\mathrm{LO}}=2 \Delta \Omega_{\mathrm{H}}-\frac{2}{3} \Delta \Omega \\
& \Delta \omega_{\mathrm{TO}}=2 \Delta \Omega_{\mathrm{H}}+\frac{1}{3} \Delta \Omega
\end{aligned}
$$

where $\Delta \Omega_{\mathrm{H}}$ is the shift due to the hydrostatic component of the applied stress and $\Delta \Omega$ is the shift due to uniaxial component of a stress tensor. Components $\Delta \Omega_{\mathrm{H}}$ and $\Delta \Omega$ can be determined using the formulas $[\underline{9}, \underline{10}]$ :

$$
\begin{aligned}
& \Delta \Omega_{\mathrm{H}}=-\gamma \omega_{0} \sigma\left(S_{11}+2 S_{12}\right) \\
& \Delta \Omega=a_{\mathrm{s}} \omega_{0} \sigma\left(S_{11}-S_{12}\right)
\end{aligned}
$$

where $\gamma$ is the Grüneisen parameter, $a_{\mathrm{s}}$ is the shear deformation potential, $S_{11}, S_{12}$ are strain tensor components characteristic for materials, and their values are available in the literature [11-13]. Determining the Raman shift values of individual $\Delta \omega_{\mathrm{LO}}$ and $\Delta \omega_{\mathrm{TO}}$ and substituting equations (3) and (4) to formulas (1) and (2), the size of the measured stress $\sigma$ can be calculated. In the case of compressive stress $\sigma$ has a negative value, while for the tensile stress $\sigma$ becomes positive.

The spectra of the two samples P199 and P201, which grew at the same temperature $645^{\circ} \mathrm{C}$, were compared (Fig. 3a). Based on the Raman shift of InAs and GaAs phonon lines, the effect of annealing QCL core was determined. In the case of sample P201, a significant increase in the intensity of TO phonons in relation to the intensity of LO was observed. Using the formulas (1)-(4), stress related to the influence of annealing QCL core was determined taking into account the phonon peaks clearly visible in the Raman spectrum. Based on the results contained in the table (Table 1), it can be con- 

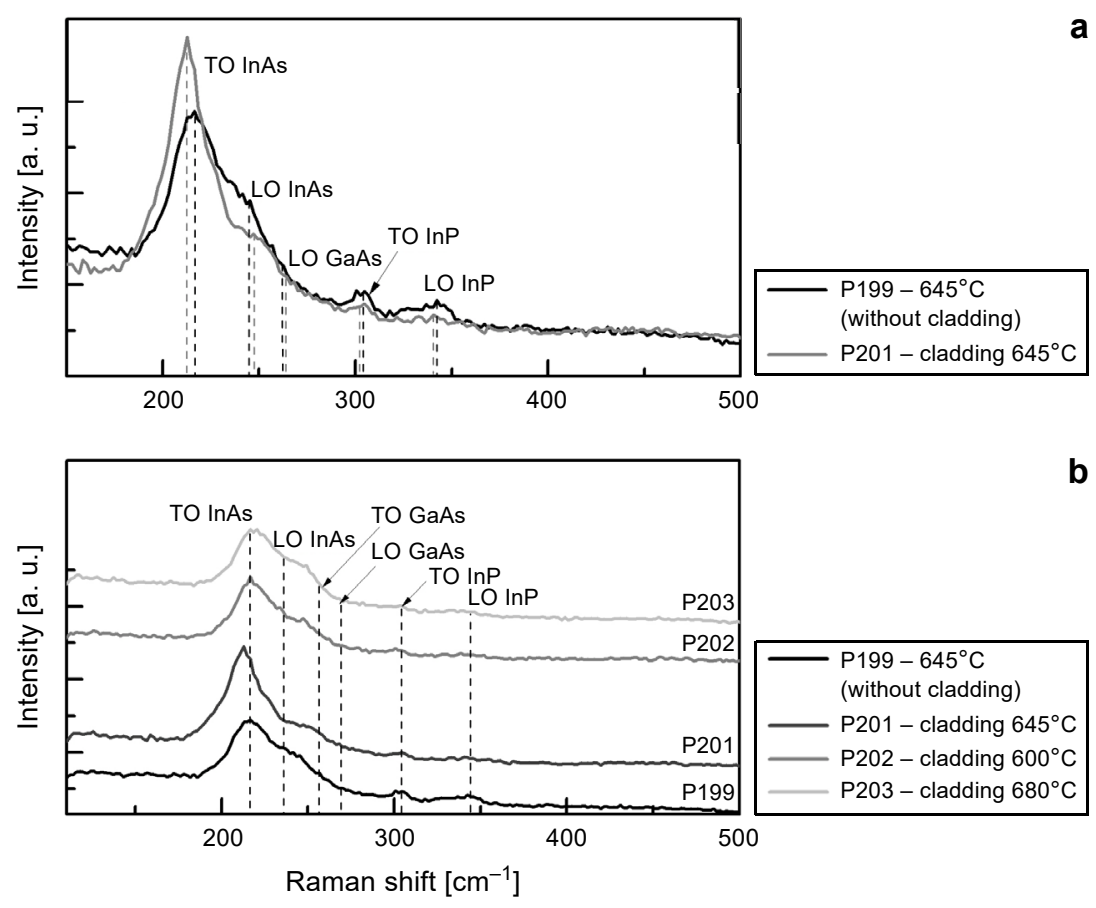

Fig. 3. Raman spectra of samples with (P201) and without cladding (P199) (a). Raman spectra of samples with cladding grown at different temperatures in comparison to the reference sample (P199) (b).

T a b l e 1. Raman shift and stress in sample P201 calculated in comparison to P199.

\begin{tabular}{llrl}
\hline Phonon line & \multicolumn{2}{l}{$\Delta \omega\left[\mathrm{cm}^{-1}\right]$} & $\sigma[\mathrm{MPa}]$ \\
\hline InAs & LO & 2.7 & 569 \\
& TO & -4.2 & 637 \\
GaAs & LO & 1.6 & 637 \\
\hline
\end{tabular}

cluded that the annealing of QCL core causes tensile stress of the order of $600 \mathrm{MPa}$. Stress values were repeatable, which means that the peaks were correctly defined.

In the next step, Raman spectra of all samples were compared to observe the influence of annealing temperature on the QCL core (Fig. 3b). The P199 sample deposited at $645^{\circ} \mathrm{C}$ without cladding was selected as a reference, which allows determining the relative stress caused by different annealing temperature. A significant influence of annealing temperature not only on the value of the Raman shift, but also on its direction was noticed. In the case of the P202 sample, a slight Raman shift is observed towards the larger values, while the peak positions in the P203 sample coincide with the reference. Positive values of Raman shifts testify to the compressive nature of stress. This effect is inverse to the effect observed in the sample P201, which proves that the annealing temperature has a critical influence on stress in QCL core. In the case of samples P202 and P203, a de- 
$\mathrm{T}$ a b le 2. Raman shift of TO InAs phonon line and stress of samples P201-P203 calculated in comparison to P199.

\begin{tabular}{lcc}
\hline Sample & $\Delta \omega\left[\mathrm{cm}^{-1}\right]$ & $\sigma[\mathrm{MPa}]$ \\
\hline $\mathrm{P} 201-645^{\circ} \mathrm{C}$ & -4.2 & 637 \\
$\mathrm{P} 202-600^{\circ} \mathrm{C}$ & 1.9 & -295 \\
$\mathrm{P} 203-680^{\circ} \mathrm{C}$ & 0.1 & -16 \\
\hline
\end{tabular}

crease in the intensity of TO phonons in relation to the quantity of LO was observed. Raman shifts determined on the basis of the graph (Fig. 3b) and calculated stress for samples P201, P202 and P203 are collected in the table (Table 2)

The smallest value of stress was calculated for the sample which was annealed at $680^{\circ} \mathrm{C}$, but the highest value for the sample which annealed temperature was the same as QCL grow temperature (Fig. 4). On the basis of the graph analysis, no linear relationship between stress and annealing temperature was found.

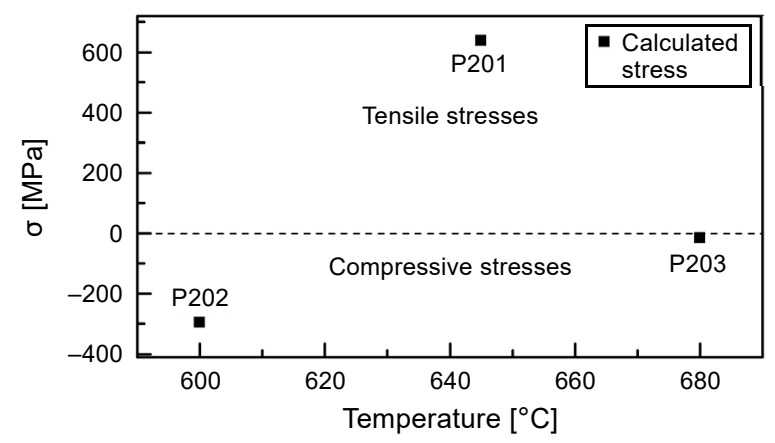

Fig. 4. Dependence between stress and annealing temperature.

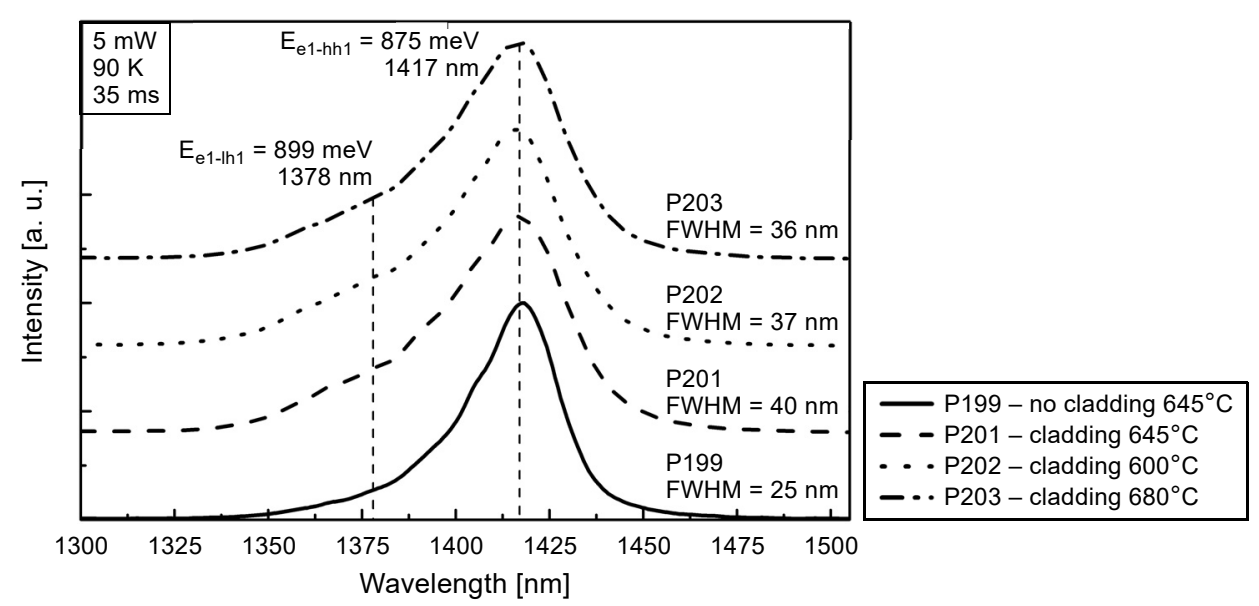

Fig. 5. Photoluminescence spectra of samples P199-P203 at $90 \mathrm{~K}$ with $5 \mathrm{~mW}$ power excitation. 
For a more accurate optical analysis of the QCL structure, photoluminescence spectra at lower temperature $90 \mathrm{~K}$ were also measured. The signal intensity value was normalized to compare the shape and broadening (full width at half maximum - FWHM) of the recorded spectra. The results of measurements and the determined optical transitions are presented on the graph (Fig. 5).

Based on the presented PL spectra results, no shift in the maximum emission position associated with the QCL core annealing process was found. However, a change in shape and widening of the PL spectrum for all samples with cladding P201-P203 was observed. For the sample annealed at the same temperature as the core growth $645^{\circ} \mathrm{C}$, the largest increase of FWHM, as well as a higher influence of additional optical transitions were observed. For samples annealed at extreme temperatures P202 $\left(600^{\circ} \mathrm{C}\right)$ and P203 $\left(680^{\circ} \mathrm{C}\right)$, an increase of FWHM of $10 \mathrm{~nm}$ was also observed, but not as much as in the case of the sample P201. A decrease in luminescence intensity from E1-lh1 transitions was also observed. Increasing the width of FWHM may be caused by the interface roughness fluctuations and compositional disorder [14, 15].

In order to compare the experiment with the theory, optical interband transitions in $\mathrm{In}_{0.53} \mathrm{Ga}_{0.47} \mathrm{As} / \mathrm{Al}_{0.48} \mathrm{In}_{0.52} \mathrm{As} \mathrm{QCL}$ core were calculated (Fig. 6). Energies of optical transitions, electron $E_{\mathrm{e}}$ and holes $E_{\mathrm{hh}}, E_{\mathrm{lh}}$ levels and wave functions are determined by a single-band Schrödinger effective-mass approximation by using nextnanomat software. Comparing the energy values of optical transitions obtained from PL spectra to the values determined in the simulation, a slight shift towards lower energies was found - $10 \mathrm{meV}$ for $E_{\mathrm{e} 1-\mathrm{hh} 1}$ and $7 \mathrm{meV}$ for $E_{\mathrm{e} 1-\mathrm{lh} 1}$. This spectrum shift may indicate graded interfaces [16] or a slight change in the thickness or composition of the designed layers (Fig. 1).

For a more detailed analysis, the effect of excitation power on the PL spectrum was also examined (Fig. 7). PL spectra were measured at different excitation powers in the range of $1-5 \mathrm{~mW}$ at $90 \mathrm{~K}$ and the acquisition time was $35 \mathrm{~ms}$. For better comparative analysis, PL spectra of all samples were normalized.

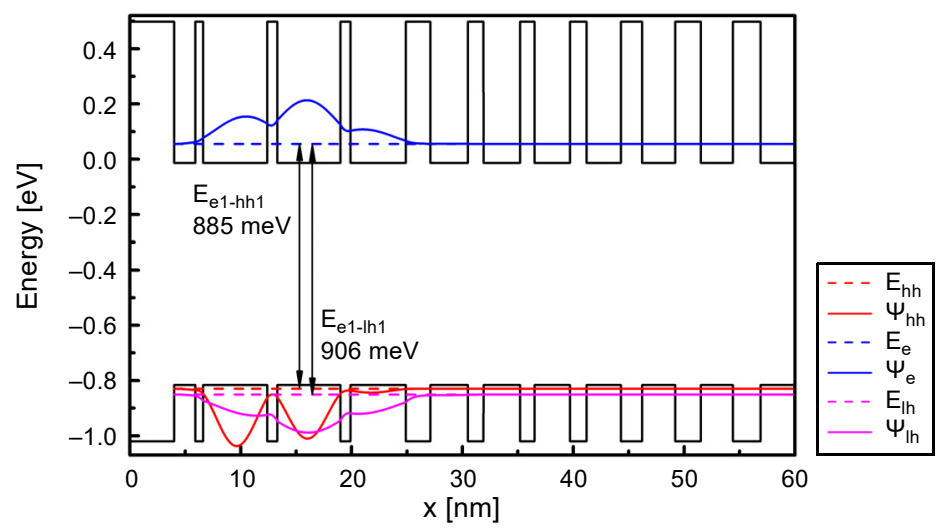

Fig. 6. Simulation of interband optical transition in $\operatorname{In}_{0.53} \mathrm{Ga}_{0.47} \mathrm{As} / \mathrm{Al}_{0.48} \mathrm{In}_{0.52} \mathrm{As}$ QCL core at $90 \mathrm{~K}$. 

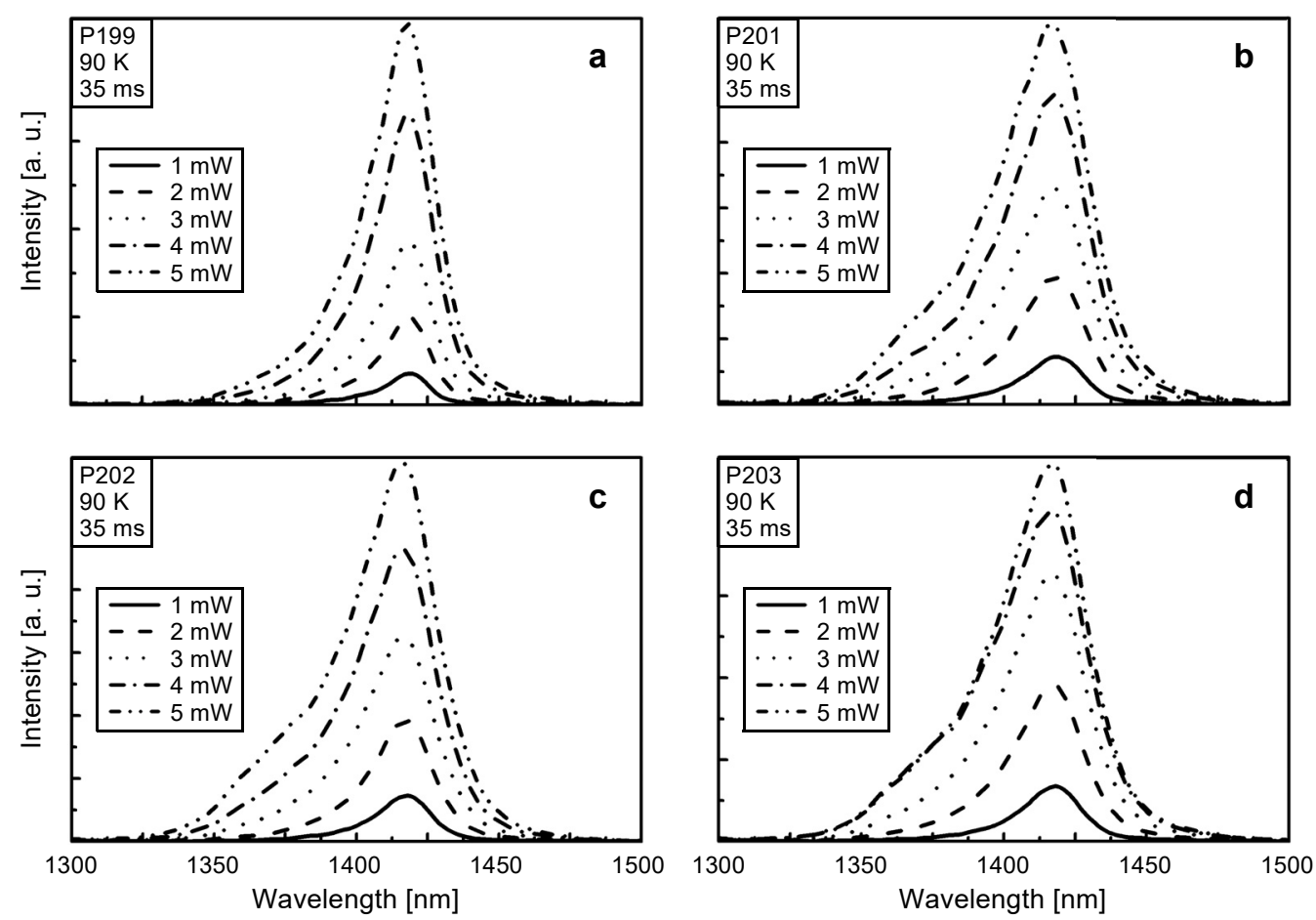

Fig. 7. Photoluminescence spectra of samples: P199 (a), P201 (b), P202 (c) and P203 (d) measured at $90 \mathrm{~K}$ with different power excitation in a range of $1-5 \mathrm{~mW}$.

Based on the PL measurements, the increasing of the excitation power in the case of the samples with the cladding layer (P201-P203), a significant contribution in luminescence coming from the $E_{\mathrm{e} 1-\mathrm{lh} 1}$ transitions was obtained. In addition, significant spectrum widening compared to the reference sample (P199) was observed. For all samples, an increase in PL intensity with an increase in excitation power was observed.

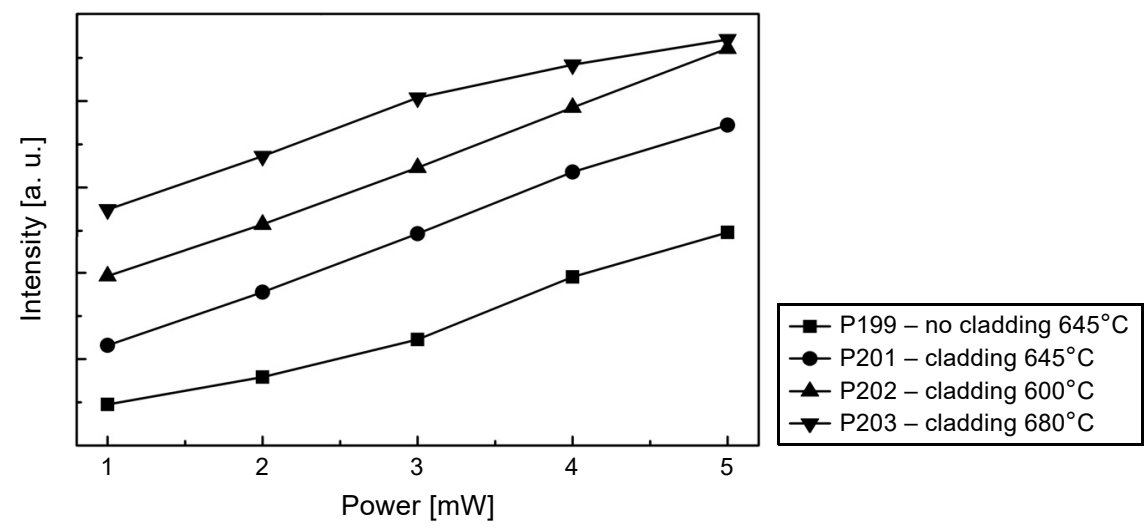

Fig. 8. Dependence of the PL intensity on the excitation power at $90 \mathrm{~K}$. 
Based on the graph (Fig.8), it was found that only the sample P202 shows a clear linear relationship between intensity and stimulation power. However, for all samples with the cladding layer (P201-P203), the linear correlation coefficient of dependence of intensity on the excitation power is improved.

\section{Conclusions}

On the basis of the presented results, the possibility of Raman and PL spectroscopies for stress and interface analysis structures as complex as QCL core was shown. In the case of such sophisticated structures as QCL, in which the core is covered by a thick layer of InP, Raman spectroscopy is not widely used mainly due to following technical difficulties. In order to probe the signal from superlattice, the measurement has to be performed in cross-section geometry, i.e. from the facet, not the surface. This measurement configuration reduces the signal intensity, which makes the analysis more complicated. Therefore, it is difficult to find a reference in literature, discussing structure of the whole device, and not only the superlattice $[\underline{17}, \underline{18}]$. The influence of annealing temperature on QCL core measured by means of photoluminescence and Raman spectroscopies was described. The presented correlation based on Raman spectroscopy analysis between stress and temperature is non-monotonic and non-linear. Similar results were obtained by another scientific group investigating QCL structures, where a non-monotonic relationship between the wavelength emitted by QCL and the annealing temperature was also observed [19]. In comparison to the sample without cladding (P199), the smallest stress value was observed for the sample which annealing temperature was $680^{\circ} \mathrm{C}$. The highest stress value was observed for the sample which cladding was grown at the same temperature $(\mathrm{P} 201)$ as the reference sample $645^{\circ} \mathrm{C}$. In the temperature range of $600-680^{\circ} \mathrm{C}$, significant changes in the nature of stress were noticed.

Based on the analysis of the measured PL spectra and theoretical simulations, the position of maximum signal emission was shifted towards smaller energies. This may be due to a deviation from the theoretical assumptions about the composition or thickness of individual layers, or a deterioration in the quality of interfaces. No shift in the PL spectrum of the annealed samples relative to the reference sample was found. The FWHM of the samples annealed at extreme temperatures $\left(\mathrm{P} 202-600^{\circ} \mathrm{C}\right.$ and $\left.\mathrm{P} 203-680^{\circ} \mathrm{C}\right)$ is similar $(36-37 \mathrm{~nm})$, however the relationship between luminescence intensity and excitation power is fully linear only for the sample annealed at the lowest temperature (P202).

Analysis of the obtained measurement results showed a correlation between the stress value and the characteristics of PL intensity measured as a function of excitation power. The high stress value may indicate high quality interfaces, which is confirmed by the linear dependence of excitation power and PL intensity. In the case of the P201 sample at higher excitation powers, a slight loss of linearity of the characteristics was observed, which may be caused by a different nature of stress than in the P202 sample. A small stress value (sample P203) may indicate reducing the sharpness of the interfaces and 
structure relaxation, which is also manifested in the analysis of PL measurements (Fig. 8). In our opinion, the results of the research presented here are promising, so we suggest that future experiments concern high resolution TEM imaging to increase the knowledge level about interfaces.

Acknowledgements - This work was co-financed by Wrocław University of Science and Technology statutory grants and by the Polish National Centre for Research and Development through project TECHMAT-STRATEG1/347510/15/NCBR/2018 (SENSE).

\section{References}

[1] Badura M., Bielak K., Ściana B., Radziewicz D., Pucicki D., Dawidowski W., Żelazna K., KudRawiec R., TŁaczaŁa M., Technology and properties of low-pressure metalorganic vapour phase epitaxy grown InGaAs/AlInAs superlattice for quantum cascade laser applications, Optica Applicata 46(2), 2016, pp. 241-248, DOI: 10.5277/oa160208.

[2] Krysa A.B., Roberts J.S., Green R.P., Wilson L.R., Page H., Garcia M., Cockburn J.W., MOVPE -grown quantum cascade lasers operating at $\sim 9 \mathrm{~m}$ wavelength, Journal of Crystal Growth 272(1-4), 2004, pp. 682-685, DOI: 10.1016/j.jcrysgro.2004.08.066.

[3] Gutowski P., Sankowska I., Karbownik P., Pierścińska D., Serebrennikova O., Morawiec M., Pruszyńska-Karbownik E., GoŁaszewska-Malec K., Pierściński K., Muszalski J., Bugajski M., MBE growth of strain-compensated InGaAs/InAlAs/InP quantum cascade lasers, Journal of Crystal Growth 466, 2017, pp. 22-29, DOI: 10.1016/j.jcrysgro.2017.02.031.

[4] Huang Y., Ryou J. H., Dupuis R. D., Pflügl C., Capasso F., Sun K., Fischer A. M., Ponce F., Optimization of growth conditions for InGaAs/InAlAs/InP quantum cascade lasers by metalorganic chemical vapor deposition, Journal of Crystal Growth 316(1), 2011, pp. 75-80, DOI: 10.1016/j.jcrysgro. 2010.12.028.

[5] Bour D., Troccoli M., Capasso F., Corzine S., Tandon A., Mars D., Höfler G., Metalorganic vapor-phase epitaxy of room-temperature, low-threshold InGaAs/AlInAs quantum cascade lasers, Journal of Crystal Growth 272(1-4), 2004, pp. 526-530, DOI: 10.1016/j.jcrysgro.2004.08.048.

[6] Wang C.A., Huang R.K., Goyal A., Donnelly J.P., Calawa D.R., Cann S.G., O’Donnell F., Plant J.J., Missaggia L.J., Turner G.W., Sanchez-Rubio A., OMVPE growth of highly strain-balanced GaInAs/AlInAs/InP for quantum cascade lasers, Journal of Crystal Growth 310(23), 2008, pp. 5191-5197, DOI: 10.1016/j.jcrysgro.2008.07.100.

[7] Matrullo N., Constant M., Sagon G., Fauquembergue R., Leroy A., Raman characterization of an operating InAlAs-InGaAs-InP high electronic mobility transistor, Journal of Raman Spectroscopy 26(2), 1995, pp. 167-172, DOI: $10.1002 /$ jrs.1250260209.

[8] Mooradian A., Wright G.B., First order Raman effect in III-V compounds, Solid State Communications 4(9), 1966, pp. 431-434, DOI: 10.1016/0038-1098(66)90321-8.

[9] Cerdeira F., Buchenauer C. J., Pollak F. H., Cardona M., Stress-induced shifts of first-order Raman frequencies of diamond-and zinc-blende-type semiconductors, Physical Review B 5(2), 1972, pp. 580 -593, DOI: 10.1103/PhysRevB.5.580.

[10] Attolini G., Francesio L., Franzosi P., Pelosi C., Gennari S., Lottici P.P., Raman scattering study of residual strain in GaAs/InP heterostructures, Journal of Applied Physics 75(8), 1994, pp. 4156 -4169, DOI: 10.1063/1.355997.

[11] Adachi S., III-V Ternary and Quaternary Compounds, [In] Springer Handbook of Electronic and Photonic Materials, [Eds.] S. Kasap, P. Capper, 2nd Ed., Springer, Cham, 2017, pp. 725-741, DOI: 10.1007/978-3-319-48933-9 30.

[12] Aoki K., ANASTASSAKIS E., CARDONA M., Dependence of Raman frequencies and scattering intensities on pressure in GaSb, InAs, and InSb semiconductors, Physical Review B 30(2), 1984, pp. 681-687, DOI: $10.1103 /$ PhysRevB.30.681. 
[13] Lockwood D.J., Yu Guolin, Rowell N.L., Optical phonon frequencies and damping in AlAs, GaP, GaAs, InP, InAs and InSb studied by oblique incidence infrared spectroscopy, Solid State Communications 136(7), 2005, pp. 404-409, DOI: 10.1016/j.ssc.2005.08.030.

[14] Wang Y., Sheng X., Guo Q., Li X., Wang S., Fu G., Mazur Y.I., Maidaniuk Y., Ware M.E, Salamo G.J, Liang B., Huffaker D.L., Photoluminescence study of the interface fluctuation effect for InGaAs/InAlAs/InP single quantum well with different thickness, Nanoscale Research Letters 12 , 2017, article 229, DOI: 10.1186/s11671-017-1998-8.

[15] Poças L.C., Duarte J.L., Lopes E.M., Dias I.F.L., Laureto E., César D.F., Harmand J.C., The effect of potential fluctuations on the optical properties of InGaAs/InGaAlAs single and coupled double quantum wells, Journal of Applied Physics 100(5), 2006, article 053519, DOI: 10.1063/1.2260826.

[16] Grroerer T.H., Photoluminescence in analysis of surfaces and interfaces, [In] Encyclopedia of Analytical Chemistry: Applications, Theory and Instrumentation, Wiley, Chichester, 2006, pp. 9209 -9231, DOI: 10.1002/9780470027318.a2510.

[17] Hu Y., Wang L., Liu F., Zhang J., Liu J., Wang Z., Micro-Raman study on chirped InGaAs-InAlAs superlattices, Physica Status Solidi A 210(11), 2013, pp. 2364-2368, DOI: 10.1002/pssa.201330002.

[18] Mozume T., KaSAI J., Micro-Raman scattering study of InGaAs/(AlAs)/AlAsSb quantum wells grown by molecular beam epitaxy, Journal of Crystal Growth 278(1-4), 2005, pp. 178-182, DOI: 10.1016 / j.jcrysgro.2004.12.072.

[19] Mathonnière S., Semtsiv M.P., Masselink W.T., Thermal annealing of lattice-matched InGaAs/ InAlAs quantum-cascade lasers, Journal of Crystal Growth 477, 2017, pp. 258-261, DOI: 10.1016 / j.jcrysgro.2017.01.029.

Received October 16, 2019 in revised form January 10, 2020 